\title{
Antibiotic overuse and allergy-related diseases: an epidemiological cross-sectional study in the grasslands of Northern China
}

This article was published in the following Dove Press journal:

Therapeutics and Clinical Risk Management

\author{
Yan Lei Chen' \\ Weirong Joshua Sng ${ }^{2}$ \\ De Yun Wang ${ }^{2}$ \\ Xue Yan Wang' \\ 'Department of Allergy, Beijing Shijitan \\ Hospital, Capital Medical University, \\ Beijing, People's Republic of China; \\ 2Department of Otolaryngology, \\ National University Health System, Yong \\ Loo Lin School of Medicine, National \\ University of Singapore, Singapore, \\ Singapore
}

Background: Several studies have shown that the use of antibiotics early in life significantly increases the risk of asthma in children. It is unclear whether antibiotics are more commonly used in patients with allergy-related diseases.

Methods: A multistage, clustered and random sampling with a field-intervieweradministrated survey study was performed to investigate if there was multiple use of antibiotics (MUA) in patients with allergic rhinitis (AR), conjunctivitis, chronic urticaria $(\mathrm{CU})$, and asthma in the grasslands of northern China. MUA was defined as antibiotic usage for at least 3 days and for more than 3 times a year in the past 2 years.

Results: A total of 5,787 subjects completed the study, with 1,079 subjects (18.6\%) identified as MUA. MUA was more common in patients with AR $(23.7 \%$ vs $16.2 \%, P<0.001)$, conjunctivitis ( $22.5 \%$ vs $17.1 \%, P<0.001)$, asthma ( $31.8 \%$ vs $17.7 \%, P<0.001)$, and CU $(25.9 \%$ vs $18.3 \%, P<0.01)$ than in subjects without allergic diseases. There is an increasing percentage of MUA in patients with a single, two, and three or more diseases both in children $(20.1 \%$, $25.0 \%$, and $31.4 \%$, respectively, $P=0.014)$ and in adults $(19.1 \%, 23.4 \%$, and $32.9 \%$, respectively, $P<0.001)$. MUA is significantly associated with AR (OR=1.7, 95\% CI: 1.3-2.1, $P<0.001)$, conjunctivitis $(\mathrm{OR}=1.6,95 \% \mathrm{CI}: 1.2-2.1, P=0.001)$, asthma $(\mathrm{OR}=2.3,95 \%$ CI:1.6-3.3, $P<0.001)$ and $\mathrm{CU}(\mathrm{OR}=2.1,95 \% \mathrm{CI}: 1.2-3.6, P=0.006)$ in children aged 2-17 years; and in adults ( $\geq 18$ years old) for $\mathrm{AR}(\mathrm{OR}=1.7,95 \% \mathrm{CI}$ : $1.4-2.1, P<0.001)$, conjunctivitis $(\mathrm{OR}=1.3,95 \% \mathrm{CI}: 1.1-1.6, P=0.002)$, and asthma (OR=2.0, 95\% CI: $1.5-2.7, P<0.001)$.

Conclusion: Antibiotic overuse might be associated with increased risk of allergy-related disease. It is important that implementation of the evidence-based international guidelines for the management of allergy-related diseases needs to be improved, in order to avoid unnecessary use of antibiotics.

Keywords: allergic rhinitis, conjunctivitis, chronic urticaria, asthma, antibiotics, epidemiology

\section{Introduction}

Antimicrobial resistance is one of the most serious public health threats today. This has been accelerated by the overuse and misuse of antimicrobials in humans and animals, as well as inadequate infection prevention. ${ }^{1,2}$ A collaborative and multidisciplinary approach specifically designed to improve antimicrobial prescriptions, together with public education about the risks and consequences of rapidly developing antibiotic resistance is hence essential in tackling this global problem. ${ }^{2}$ In addition, factors contributing to antibiotic misuse need to be investigated and strictly avoided in the future.
Correspondence: Xue Yan Wang Department of Allergy, Beijing Shijitan Hospital, Capital Medical University, No.I0, Tieyi Road, Haidian District, Beijing 100038, People's Republic of China Tel +860 1063926072

Email wangxueyan2018@163.com 
Allergic rhinoconjunctivitis and asthma, common allergic diseases globally, can be caused by an interplay of genetic and environmental factors. ${ }^{3,4}$ Common nasal symptoms (eg, rhinorrhea and nasal obstruction) and respiratory symptoms (eg, cough and wheeze) which can be observed in these allergic (non-infectious) conditions are also common in infectious conditions. It is thus a challenging and yet important question as to when antibiotics should be used in patients presenting with such symptoms. In recent years, a number of studies have shown that the use of antibiotics in infants may increase the risk of allergic rhinitis (AR) or asthma. ${ }^{5,6}$ However, only a limited number of epidemiological studies have been done on the relationship between antibiotic use and allergy-related diseases.

A recent epidemiologic study demonstrated an extremely high prevalence of pollen-induced AR due to high seasonal pollen exposure in the grasslands of northern China. ${ }^{7}$ Our aim was to provide further detailed information on potential risks for multiple use of antibiotics (MUA) in patients with common allergy-related diseases.

\section{Methods}

\section{Study population}

A multistage, clustered and random sampling with a fieldinterviewer-administrated survey study was performed from May to August 2015 in the grasslands of northern China. Based on data obtained from the 2010 Chinese nationwide population census, the total population in the study region was 1.74 million (urban: 730,928; rural: $1,011,696)$. The sample calculation was based on an estimated prevalence of $15 \%$ for allergy-related diseases, to reach a significance level (alpha) of 0.05 and error tolerance $0.10 \mathrm{p}$, the estimated sample size was 6,000 with equal distribution in urban and rural areas, and with the same gender and age stratification.

The details of the study design and conduct of the study have been previously reported. ${ }^{7}$ Briefly, in the selected clusters (eg, villages from rural areas and street districts from urban areas), all members from a household were invited to participate in this study. They reported to the survey manager with their national registration identity card and signed the informed consent form before participating in this study. For children or teenagers aged less than 18 years, the informed consent was signed by their parents or guardians who accompanied them to the survey site. All study subjects were investigated using an interviewer-administered questionnaire at a medical center or hospital near their home. We then carried out a post hoc statistical analysis of MUA in patients with AR, conjunctivitis, chronic urticaria (CU), and asthma in both children and adult in this region. Approval to conduct this study was granted by the institutional review boards of Beijing Shijitan Hospital, the affiliated hospital of the Beijing Capital Medical University, and of all local participating municipalities.

\section{Definitions used in this study}

The diagnosis of all four diseases was made based on symptoms which were common and suggestive of the respective diseases, and are reported in international guidelines or used in other epidemiological studies.

- AR: Subjects were diagnosed as having AR if they had at least two of the four symptoms suggestive of AR (itchy nose, sneezing, runny, and blocked nose) for at least $1 \mathrm{hr}$ on most days during the past year were diagnosed with "epidemiological AR". ${ }^{3}$

- Conjunctivitis: Subjects were diagnosed as having conjunctivitis the basis of positive answers to the written question: "Have you had itchy or red or watery eyes in the past 12 months?",,9

- Asthma: We estimated asthma symptoms on the basis of positive answers to the written question:" Have you ever been diagnosed with asthma? Have you/Has your child had any of the following symptoms during the past year? (i) Wheezing; (ii) Cough; (iii) Dyspnea; (iv) Chest tightness."

- CU: Subjects were diagnosed with CU on the basis of positive answers to the written question: "Wheal occurs twice a week at least, and disappears within $24 \mathrm{hrs}$, lasting at least six weeks" in the past 12 months. $^{12}$

- MUA: Subjects were defined as having had MUA if they had used antibiotics for at least 3 days on each occasion and for more than 3 times a year in the past 2 years.

\section{Statistical analyses}

All tests were two-sided with a significant level of $<0.05$. All analyses were performed using SPSS22.0 (SPSS Inc., Chicago, IL, USA). Between-group differences in subject characteristics were analyzed using chi-square/Fisher exact test for categorical variables. Multivariate logistic regression analysis was performed to estimate the risk factors related to MUA and estimate their odds ratio among the four common 
allergy-related diseases. Comparison of the presence of MUA in allergic patients presenting single or combined diseases was done using Linear-by-Linear Association Chi-Square Test.

\section{Results}

A total of 5,944 subjects were surveyed with 5,787 valid questionnaires (effective 97.36\%). Among them, there were 2,261 children (aged 2-17 years) and 3,526 adults (aged 18 years or more). One hundred and fifty-seven questionnaires ( $2.64 \%$, from 83 children and 74 adults) were excluded from the final analysis, because these subjects were not clear with their history of antibiotic usage during the past 2 years. We also did not include children younger than 2 years due to the definition of MUA. Overall, MUA was found in 1,079 subjects $(18.6 \%)$ and was more common in patients with AR $(23.7 \%$ vs $16.2 \%, P<0.001$ ), conjunctivitis ( $22.5 \%$ vs $17.1 \%, P<0.001$ ), asthma ( $31.8 \%$ vs $17.7 \%, P<0.001)$, and CU $(25.9 \%$ vs $18.3 \%$, $P<0.01$ ) than in subjects without allergic diseases (Table 1).

\section{The prevalence of allergy-related diseases in children and their relationship with MUA}

In children $(\mathrm{n}=2261)$, the prevalence of $\mathrm{AR}$, conjunctivitis, asthma, and $\mathrm{CU}$ was $27.5 \%, 18.2 \%, 6.9 \%$, and $3.0 \%$, respectively (Table 1). A significantly higher rate of MUA $(n=421)$

Table I Demographics characteristics of the study subjects

\begin{tabular}{|c|c|c|c|c|c|c|c|c|}
\hline \multirow[t]{3}{*}{ Characteristic } & \multicolumn{4}{|c|}{ Adults } & \multicolumn{4}{|c|}{ Children } \\
\hline & Total & MUA & NMUA & $P$-value & Total & MUA & NMUA & $P$-value \\
\hline & 3,526 & 658 & 2,868 & & 2,261 & 421 & 1,840 & \\
\hline $\begin{array}{l}\text { Gender, n (\%) } \\
\text { Male } \\
\text { Female }\end{array}$ & $\begin{array}{l}1,611 \\
1,915\end{array}$ & $\begin{array}{l}254(15.8) \\
404(21.1)\end{array}$ & $\begin{array}{l}\mathrm{I}, 357(84.2) \\
\mathrm{I}, 5 \mathrm{II}(88.9)\end{array}$ & $<0.001$ & $\begin{array}{l}\mathrm{I}, 158 \\
\mathrm{I}, 103\end{array}$ & $\begin{array}{l}222(19.2) \\
199(18.0)\end{array}$ & $\begin{array}{l}936(80.8) \\
904(82.0)\end{array}$ & 0.490 \\
\hline $\begin{array}{l}\text { Race, n (\%) } \\
\text { Han } \\
\text { Mongolian } \\
\text { Others }\end{array}$ & $\begin{array}{l}2,055 \\
1,334 \\
137\end{array}$ & $\begin{array}{l}399(19.4) \\
233(17.5) \\
26(19.0)\end{array}$ & $\begin{array}{l}\mathrm{I}, 656(80.6) \\
\mathrm{I}, \mathrm{IOI}(82.5) \\
\mathrm{III}(8 \mathrm{I} .0)\end{array}$ & 0.370 & $\begin{array}{l}1,102 \\
1,037 \\
122\end{array}$ & $\begin{array}{l}195(17.7) \\
208(20.1) \\
18(14.8)\end{array}$ & $\begin{array}{l}907(82.3) \\
829(80.0) \\
104(85.3)\end{array}$ & 0.198 \\
\hline $\begin{array}{l}\text { Area of residence, } \mathrm{n}(\%) \\
\text { Urban } \\
\text { Rura }\end{array}$ & $\begin{array}{l}1,709 \\
1,817\end{array}$ & $\begin{array}{l}383(22.4) \\
275(15.13)\end{array}$ & $\begin{array}{l}\mathrm{I}, 326(77.6) \\
\mathrm{I}, 542(84.87)\end{array}$ & $<0.001$ & $\begin{array}{l}1,151 \\
1,110\end{array}$ & $\begin{array}{l}249(21.6) \\
172(15.50)\end{array}$ & $\begin{array}{l}902(78.4) \\
938(84.50)\end{array}$ & $<0.001$ \\
\hline $\begin{array}{l}\text { Family allergy history, n (\%) } \\
\text { Yes } \\
\text { No } \\
\text { Unknown }\end{array}$ & $\begin{array}{l}1,131 \\
2,292 \\
103\end{array}$ & $\begin{array}{l}350(30.95) \\
290(12.7) \\
18(17.5)\end{array}$ & $\begin{array}{l}781(69.05) \\
2,002(87.4) \\
85(82.5)\end{array}$ & $<0.001$ & $\begin{array}{l}780 \\
1,427 \\
54\end{array}$ & $\begin{array}{l}207(26.54) \\
210(14.7) \\
4(7.4)\end{array}$ & $\begin{array}{l}573(73.46) \\
1,217(85.3) \\
50(92.6)\end{array}$ & $<0.001$ \\
\hline \multicolumn{9}{|l|}{ Allergy-related diseases } \\
\hline $\begin{array}{l}\text { Allergic rhinitis (AR), n (\%) } \\
\text { Yes } \\
\text { No }\end{array}$ & $\begin{array}{l}1,278 \\
2,248\end{array}$ & $\begin{array}{l}308(24.1) \\
350(15.6)\end{array}$ & $\begin{array}{l}970(75.9) \\
1,898(84.4)\end{array}$ & $<0.001$ & $\begin{array}{l}621 \\
1,640\end{array}$ & $\begin{array}{l}142(22.9) \\
279(17.0)\end{array}$ & $\begin{array}{l}479(77.1) \\
I, 36 \mid(83.0)\end{array}$ & 0.001 \\
\hline $\begin{array}{l}\text { Conjunctivitis, n (\%) } \\
\text { Yes } \\
\text { No }\end{array}$ & $\begin{array}{l}1,220 \\
2,306\end{array}$ & $\begin{array}{l}27 \mid(22.2) \\
387(16.8)\end{array}$ & $\begin{array}{l}949(77.8) \\
1,919(83.2)\end{array}$ & $<0.001$ & $\begin{array}{l}412 \\
1,849\end{array}$ & $\begin{array}{l}96(23.3) \\
325(17.6)\end{array}$ & $\begin{array}{l}316(76.7) \\
1,524(82.4)\end{array}$ & 0.007 \\
\hline $\begin{array}{l}\text { Chronic urticarial (CU), n (\%) } \\
\text { Yes } \\
\text { No }\end{array}$ & $\begin{array}{l}191 \\
3,335\end{array}$ & $\begin{array}{l}44(23.0) \\
614(18.4)\end{array}$ & $\begin{array}{l}\mid 47(76.9) \\
2,72 \mid(81.6)\end{array}$ & 0.111 & $\begin{array}{l}68 \\
2,193\end{array}$ & $\begin{array}{l}23(33.8) \\
398(18.2)\end{array}$ & $\begin{array}{l}45(66.2) \\
1,795(81.9)\end{array}$ & 0.001 \\
\hline $\begin{array}{l}\text { Asthma } \\
\text { Yes } \\
\text { No }\end{array}$ & $\begin{array}{l}219 \\
3,307\end{array}$ & $\begin{array}{l}69(31.5) \\
589(17.8)\end{array}$ & $\begin{array}{l}150(68.5) \\
2,7 \mid 8(82.2)\end{array}$ & $<0.001$ & $\begin{array}{l}155 \\
2,106\end{array}$ & $\begin{array}{l}50(32.3) \\
37 I(I 7.6)\end{array}$ & $\begin{array}{l}105(67.7) \\
1,735(82.4)\end{array}$ & $<0.001$ \\
\hline
\end{tabular}

Abbreviations: MUA, multiple uses of antibiotics; NMUA, non-MUA. 
was found in children with either AR, conjunctivitis, asthma, or $\mathrm{CU}$ as compared to patients from the non-disease group (Table 2).

After correcting for other factors the risk of MUA is increased significantly in $\mathrm{AR}(\mathrm{OR}=1.7,95 \% \mathrm{CI}=1.3-2.1$, $P<0.001)$, conjunctivitis ( $\mathrm{OR}=1.6,95 \% \quad \mathrm{CI}=1.2-2.1$, $P=0.001)$, asthma ( $\mathrm{OR}=2.3,95 \% \mathrm{CI}=1.6-3.3, P<0.001)$, and $\mathrm{CU}(\mathrm{OR}=2.1,95 \% \mathrm{CI}=1.2-3.6, P=0.006)$, respectively as compared to allergy-related disease-free individuals.

\section{The prevalence of allergy-related diseases in adults and their relationship with MUA}

In adults $(\mathrm{n}=3526)$, the prevalence of $\mathrm{AR}$, conjunctivitis, asthma, and CU was $36.3 \%, 34.6 \%, 6.2 \%$, and $5.4 \%$, respectively. A significantly higher rate of MUA ( $n=658)$ was found in adults with AR, conjunctivitis, and asthma but not $\mathrm{CU}$ as compared to patients from the non-disease group (Table 3). After correcting for other factors the risk of MUA has increased in AR (OR=1.7, 95\% CI $=1.4-2.1$,

Table 2 Comparison of the prevalence of all four diseases in children with MUA

\begin{tabular}{|l|l|l|l|l|}
\hline Diseases & MUA & NMUA & $X^{2}$ value & P-value \\
\hline $\begin{array}{l}\text { Allergic rhinitis, n (\%) } \\
\text { Yes } \\
\text { No }\end{array}$ & $\begin{array}{l}142(33.7) \\
279(67.3)\end{array}$ & $\begin{array}{l}479(26.0) \\
1,361(74.0)\end{array}$ & 10.187 & 0.001 \\
\hline $\begin{array}{l}\text { Asthma, n (\%) } \\
\text { Yes }\end{array}$ & $\begin{array}{l}9(22.8) \\
\text { No }\end{array}$ & $325(77.2)$ & $316(17.2)$ & \\
\hline $\begin{array}{l}\text { Conjunctivitis, n (\%) } \\
\text { Yes } \\
\text { No }\end{array}$ & $50(11.9)$ & 7.285 & 0.007 \\
\hline $\begin{array}{l}\text { Chronic urticaria, n (\%) } \\
\text { Yes }\end{array}$ & $371(88.1)$ & $105(5.7)$ & $1,735(94.3)$ & 20.426 \\
No & $23(5.5)$ & $45(2.4)$ & $1,795(97.6)$ & $<0.001$ \\
\hline
\end{tabular}

Note: Chi-squared test was performed in this table. The results have been confirmed by adjusting the common variables and confounding factors, such as age, gender, ethnicity, and living area (urban or rural) using multivariate logistic regression analysis.

Abbreviations: MUA, multiple uses of antibiotics; NMUA, non-MUA.

Table 3 Comparison of the prevalence of all four diseases in adults with MUA

\begin{tabular}{|c|c|c|c|c|}
\hline Diseases & MUA & NMUA & $X^{2}$ value & $P$-value \\
\hline \multicolumn{5}{|l|}{ Allergic rhinitis, n (\%) } \\
\hline Yes & $308(46.8)$ & $970(33.8)$ & 39.064 & $<0.001$ \\
\hline No & $350(53.2)$ & I,898 (66.2) & & \\
\hline \multicolumn{5}{|l|}{ Asthma, n (\%) } \\
\hline Yes & $69(10.5)$ & $150(5.2)$ & 25.384 & $<0.001$ \\
\hline No & $589(89.5)$ & $2,718(94.8)$ & & \\
\hline \multicolumn{5}{|l|}{ Conjunctivitis, n (\%) } \\
\hline Yes & $27 \mid(4 I .2)$ & $949(33.1)$ & 15.503 & $<0.001$ \\
\hline No & $387(58.8)$ & $1,919(66.9)$ & & \\
\hline \multicolumn{5}{|l|}{ Chronic urticaria, n (\%) } \\
\hline Yes & $44(6.7)$ & $147(5.4)$ & 2.547 & 0.111 \\
\hline No & $614(93.3)$ & $2,72 \mid(94.6)$ & & \\
\hline
\end{tabular}

Note: Chi-squared test was performed in this table. The results have been confirmed by adjusting the common variables and confounding factors, such as age, gender, ethnicity, and living area (urban or rural) using multivariate logistic regression analysis.

Abbreviations: MUA, multiple uses of antibiotics; NMUA, non-MUA. 
$P<0.001)$; conjunctivitis $\quad(\mathrm{OR}=1.3, \quad 95 \% \quad \mathrm{CI}=1.1-1.6$, $P=0.002)$, and asthma $(\mathrm{OR}=2.0,95 \% \quad \mathrm{CI}=1$. 5-2.7, $P<0.001)$ as compared to allergic disease-free individuals. The risk of MUA in CU compared to allergic disease-free individuals was not shown to be significantly elevated $(\mathrm{OR}=1.3,95 \% \mathrm{CI}=0.9-1.8, P=0.199)$.

\section{Relationship between MUA and the number of allergy-related diseases}

An increase in the number of allergy-related diseases that patients had resulted in a statistically significant higher incidence of MUA in both children and adults. The increase in incidence of MUA correlated with the increase in the number of allergy-related diseases that patients had (ie, a patient with more allergy-related diseases was more likely to have a higher incidence of MUA than a patient with less or none) (Table 4).

\section{Discussion}

$\mathrm{AR}$, conjunctivitis, asthma, and CU are common allergyrelated diseases that affect both children and adults worldwide. The patient can have either a single or multiple disease manifestations simultaneously due to common causal pathways (eg, allergy). ${ }^{13}$ This can seriously affect the patient's health and quality of life. In this study, the prevalence of all four diseases is considerably high due to seasonal pollen exposure in the grasslands. ${ }^{7}$

Recent studies suggest that antibiotics in the first few years of life have been associated with increased risks of allergic disease in later childhood. ${ }^{14}$ Some studies have shown that exposure and use of antibiotics in infants may increase the risk of AR or asthma. ${ }^{5,6,15,16}$ Other studies have shown that there is a direct relationship between antibiotic use in the first 3 years of life and asthma and allergy symptoms in children aged 6-8 years old. ${ }^{17}$ A prospective birth cohort study in Taiwan showed that exposure to antibiotics influences the development of common allergic diseases in later childhood. ${ }^{18}$ However, studies on the relationship between MUA inpatients (both children and adults) with allergy-related diseases have not been systemically reported worldwide.

Antibiotics are important medications in treating bacterial infections, preventing the spread of disease and reducing serious complications of the disease. However, the overuse and misuse of antibiotics are key factors contributing to antibiotic resistance, which is one of the most serious public health threats today. ${ }^{19}$ In a recently published Chinese consensus report on the evaluation and management of asthma exacerbation, it has a special statement that overuse of antibiotics should be avoided. ${ }^{20}$

The results of the epidemiological survey showed that the prevalence of AR, conjunctivitis, asthma, and $\mathrm{CU}$ was increased significantly in children aged 2-17 years old who had MUA compared with children with non-MUA (NMUA). Similarly, the prevalence of adult AR, conjunctivitis, and asthma was also significantly higher in patients with MUA than those with NMUA. This is suggestive that antibiotics may be associated with increased risk of allergic diseases in later life, although no causality can be proven in this study. At the same time, compared with patients who had no multiple antibiotic use, the prevalence of multiple antibiotic users across the different age groups increased with the increasing number of common allergy-related diseases.

Although it is certainly possible that patients with an increasing number of common allergy-related diseases require treatment with more courses of antibiotics, it is nonetheless suggestive that the MUA was more likely to cause allergic syndromes. Physiologically, the human

Table 4 Comparison of the presence of MUA in allergic patients presenting single or combined diseases

\begin{tabular}{|l|l|l|l|l|l|}
\hline Disease type & Number & MUA $^{\mathbf{a}}$ & Rate of MUA(\%) & $\boldsymbol{X}^{\mathbf{2}}$ value $^{\mathbf{b}}$ & $\boldsymbol{P}_{\text {-value }}$ \\
\hline Children & & & & 6.059 & 0.014 \\
- One disease & 447 & 90 & 20.1 & & \\
- Two diseases & 272 & 68 & 25.0 & & \\
- Three or more diseases & 86 & 27 & & & \\
\hline Adults & & 180 & 19.1 & $<0.399$ & \\
- One disease & 944 & 167 & 23.4 & & \\
- Two diseases & 715 & 57 & 32.9 & \\
- Three or more diseases & 173 & & \\
\hline
\end{tabular}

Notes: ${ }^{a}$ Number of patients with MUA. 'binear-by-Linear Association Chi-Square Test. Abbreviations: MUA, multiple uses of antibiotics; NMUA, non-MUA. 
mucosa has a large number of harmless commensal organisms, and this respiratory symbiosis is vital to the normal function of the respiratory tract. Any change to the mucosal immune system could lead to changes in the composition of the symbiotic bacteria, which in turn may affect the response of the mucosal immune system to other immune stimuli. ${ }^{21,22}$ Hence, multiuse of antibiotics might thus increase the risk of immune dysfunction and allergic diseases. More than $80 \%$ of the patients with asthma had concomitant rhinitis, and $10-40 \%$ of the patients with rhinitis had concomitant asthma, ${ }^{22}$ which lends credence to the concept of "one airway, one disease". 3 It has also been shown that urticaria is a common co-morbidity of asthma, ${ }^{23}$ and also has significant correlation with $\mathrm{AR}$ and asthma. ${ }^{24}$ However, the increased risk of $\mathrm{CU}$ in different age groups was not consistent. The specific causes and mechanism of CU are unknown, and studies are needed to elucidate this further.

There are several limitations to this epidemiological investigation. As this was designed as a cross-sectional study, results could be subject to recall bias. Further, it cannot be determined at this point if the observed associations are indeed causal or are a result of confounding by indication or reverse causation.

\section{Conclusion}

This study has demonstrated that MUA is more prevalent in patients with allergy-related diseases. However, we are not able to draw conclusions on the causality between the observed differences. Antibiotics are important in the treatment and prevention of complications of many bacterial illnesses, but the misuse of antibiotics is also a serious global public health issue. At present, the causality and specific mechanism of MUA being more prevalent in patients with allergy-related diseases needs to be further explored and studied. More research should be done to allow there to be a consensus on the appropriate use of antibiotics, especially in patients with allergy-related diseases.

\section{Ethical approval}

Approval to conduct this study was granted by the institutional review boards of Beijing Shijitan Hospital, the affiliated hospital of the Beijing Capital Medical University, and of all six participating municipalities. All respondents signed informed consent.

\section{Acknowledgments}

This study was supported by the National Key Specialty Funding of China (health and Family Planning Commission-16) and Beijing Municipal Administration of Hospitals Clinical Medicine Development of Special Funding Support (ZYLX201826).

\section{Disclosure}

The authors report no conflicts of interest in this work.

\section{References}

1. Septimus EJ. Antimicrobial resistance: an antimicrobial/diagnostic stewardship and infection prevention approach. Med Clin North Am. 2018;102(5):819-829. doi:10.1016/j.mcna.2018.04.005

2. Medina E, Pieper DH. Tackling threats and future problems of multidrug-resistant bacteria. Curr Top Microbiol Immunol. 2016;398:3-33. doi:10.1007/82_2016_492

3. Bousquet J, Khaltaev N, Cruz AA, et al. Allergic rhinitis and its impact on asthma (ARIA) 2008 update (in collaboration with the World Health Organization, GA(2)LEN and AllerGen). Allergy. 2008;63(Suppl 86):8-160. doi:10.1111/j.1398-9995.2007.01620.x

4. Global Initiative for Asthma [homepage on the Internet]. Global strategy for asthma management and prevention; 2014. Available from: www.ginasthma.org. Accessed June 26, 2017.

5. Yamamoto-Hanada K, Yang L, Narita M, et al. Influence of antibiotic use in early childhood on asthma and allergic diseases at age 5. Ann Allergy Asthma Immunol. 2017;119(1):54-58. doi:10.1016/ j.anai.2017.05.013

6. Yoon J, Choi YJ, Lee E, et al. Allergic rhinitis in preschool children and the clinical utility of FeNO. Allergy Asthma Immunol Res. 2017;9 (4):314-321. doi:10.4168/aair.2017.9.4.314

7. Wang XY, Ma TT, Wang XY, et al. Prevalence of pollen-induced allergic rhinitis with high pollen exposure in grasslands of northern China. Allergy. 2018;73(6):1232-1243. doi:10.1111/all.13388

8. Asher MI, Montefort S, Björkstén B, et al. Worldwide time trends in the prevalence of symptoms of asthma, allergic rhinoconjunctivitis, and eczema in childhood: ISAAC phases one and three repeat multicountry cross-sectional surveys. Lancet. 2006;368(9537):733-743. doi:10.1016/S0140-6736(06)69283-0

9. Thong BY. Allergic conjunctivitis in Asia. Asia Pac Allergy. 2017;7 (2):57-64. doi:10.5415/apallergy.2017.7.2.57

10. Bateman ED, Hurd SS, Barnes PJ, et al. Global strategy for asthma management and prevention: GINA executive summary. Eur Respir J. 2008;31(1):143-178. doi:10.1183/09031936.00138707

11. De MR, Zanolin ME, Accordini S, et al. A new questionnaire for the repeat of the first stage of the European Community Respiratory Health Survey: a pilot study. Eur Respir J. 1999;14 (5):1044-1048.

12. Zuberbier T, Aberer W, Asero R, et al. The EAACI/GA(2) LEN/EDF/ WAO guideline for the definition, classification, diagnosis, and management of urticaria: the 2013 revision and update. Allergy. 2014;69 (7):868-887. doi:10.1111/all.12313

13. Busse WW, Holgate ST. Asthma and Rhinitis. Oxford: Blacckwell Scientific Publications; 1995.

14. Crane J. Asthma and allergic diseases: is there a downside to cleanliness and can we exploit it? Eur J Clin Nutr. 2002;56(Suppl 4):S39S43. doi:10.1038/sj.ejen. 1601660

15. Han YY, Forno E, Badellino HA, et al. Antibiotic use in early life, rural residence, and allergic diseases in Argentinean children. $J$ Allergy Clin Immunol Pract. 2017;5(4):1112-1118. 
16. Singh S, Sharma BB, Salvi S, et al. Allergic rhinitis, rhinoconjunctivitis, and eczema: prevalence and associated factors in children. Clin Respir J. 2018;12(2):547-556. doi:10.1111/crj.12561

17. Raciborski F, Tomaszewska A, Komorowski J, et al. The relationship between antibiotic therapy in early childhood and the symptoms of allergy in children aged 6-8 years - the questionnaire study results. Int J Occup Med Environ Health. 2012;25(4):470-480. doi:10.2478/S13382-012-0056-0

18. Wang JY, Liu LF, Chen CY, et al. Acetaminophen and/or antibiotic use in early life and the development of childhood allergic diseases. Int J Epidemiol. 2013;42(4):1087-1099. doi:10.1093/ije/dyt121

19. US Food and Drug Administration. Battle of the bugs: fighting antibiotic resistance. FDA Consum. 2002;36(4):28-34.

20. Asthma Group of Chinese Thoracic Society; China Asthma Alliance. [The Chinese experts' consensus on the evaluation and management of asthma exacerbation]. [Article in Chinese]. Zhonghua Nei Ke Za Zhi. 2018;57(1):4-14. doi:10.3760/cma.j. issn.0578-1426.2018.01.002
21. Marsland BJ, Gollwitzer ES. Host-microorganism interactions in lung disease. Nat Rev Immunol. 2014;14(12):827-835. doi:10.1038/ nri3769

22. Gill N, Wlodarska M, Finlay BB. The future of mucosal immunology: studying an integrated system-wide organ. Nat Immunol. 2010;11(7):558-560. doi:10.1038/ni0710-558

23. Ghio AJ. Asthma as a disruption in iron homeostasis. Biometals. 2016;29(5):751-779. doi:10.1007/s10534-016-9948-y

24. Chiu HY, Muo CH, Sung FC. Associations of chronic urticaria with atopic and autoimmune comorbidities: a nationwide population-based study. Int $J$ Dermatol. 2018;57(7):822-829. doi:10.1111/ijd.14000
Therapeutics and Clinical Risk Management

\section{Publish your work in this journal}

Therapeutics and Clinical Risk Management is an international, peerreviewed journal of clinical therapeutics and risk management, focusing on concise rapid reporting of clinical studies in all therapeutic areas, outcomes, safety, and programs for the effective, safe, and sustained use of medicines. This journal is indexed on PubMed Central, CAS,

\section{Dovepress}

EMBase, Scopus and the Elsevier Bibliographic databases. The manuscript management system is completely online and includes a very quick and fair peer-review system, which is all easy to use. Visit http://www.dovepress.com/testimonials.php to read real quotes from published authors. 